\title{
Intricate crosstalk between MYB and noncoding RNAs in cancer
}

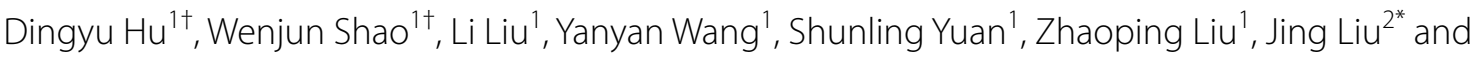 \\ Ji Zhang ${ }^{1,3^{*}}$ (D)
}

\begin{abstract}
MYB is often overexpressed in malignant tumors and plays a carcinogenic role in the initiation and development of cancer. Deletion of the MYB regulatory C-terminal domain may be a driving mutation leading to tumorigenesis, therefore, different tumor mechanisms produce similar MYB proteins. As MYB is a transcription factor, priority has been given to identifying the genes that it regulates. All previous attention has been focused on protein-coding genes. However, an increasing number of studies have suggested that MYB can affect the complexity of cancer progression by regulating tumor-associated noncoding RNAs (ncRNAs), such as microRNAs, long-non-coding RNAs and circular RNAs. ncRNAs can regulate the expression of numerous downstream genes at the transcription, RNA processing and translation levels, thereby having various biological functions. Additionally, ncRNAs play important roles in regulating MYB expression. This review focuses on the intricate crosstalk between oncogenic MYB and ncRNAs, which play a pivotal role in tumorigenesis, including proliferation, apoptosis, angiogenesis, metastasis, senescence and drug resistance. In addition, we discuss therapeutic strategies for crosstalk between MYB and ncRNAs to prevent the occurrence and development of cancer.
\end{abstract}

Keywords: MYB, Noncoding RNAs, LncRNAs, MiRNAs, Tumorigenesis

\section{Introduction}

The MYB gene was discovered from virus MYB ( $V-M Y B)$, which is the oncogene of avian myeloblastosis virus (AMV) and E26 (another avian virus), and is considered a causative the oncogene of avian myeloma and lymphoma in birds. This has led, to the hypothesis that aberrant activation of vertebrate MYB could also cause cancer [1]. Moreover, the nucleotide sequence of the promoter region of the MYB proto-oncogene was detected in mice,

\footnotetext{
*Correspondence: liujing2@sklmg.edu.cn; jizhang@fsyy.usc.edu.cn ${ }^{\dagger}$ Dingyu Hu and Wenjun Shao have contributed equally to this work ${ }^{1}$ The First Affiliated Hospital, Department of Rheumatology, Hengyang Medical School, University of South China, Hengyang 421001, Hunan, China

${ }^{2}$ Hunan Province Key Laboratory of Basic and Applied Hematology, Molecular Biology Research Center \& Center for Medical Genetics, School of Life Sciences, Central South University, Changsha 410078, Hunan, China

Full list of author information is available at the end of the article
}

humans, lizards, frogs, and carp, indicating that this evolutionarily conserved element is involved in the regulation of MYB proto-oncogene expression in vertebrates [2]. The MYB protein contains a DNA-binding domain (DBD) at the N-terminal, which consists of three tandem repeat domains of approximately 50 amino acids containing tryptophan, named R1, R2 and R3; a conserved $\mathrm{C}$-terminal negative regulatory domain (NRD); and a transactivation domain (TAD) located in the central part of the protein (Fig. 1) [3]. Evidence suggests that deletion of MYB regulatory C-terminal domain may be a driving mutation leading to tumorigenesis [1]. In leukemia samples, enhanced alternative RNA splicing produces mutated MYB gene transcripts [4]. Moreover, recurrent $\mathrm{t}(6 ; 9)$ (q22-23; p23-24) translocation in adenoid cystic carcinoma fuse MYB gene on chromosome 6 to NFIB gene on chromosome 9 [5]. Cellular MYB (c-MYB) is a homolog of $v-M Y B$, which paved the way for the original author(s) and the source, provide a link to the Creative Commons licence, and indicate if changes were made. The images or other third party material in this article are included in the article's Creative Commons licence, unless indicated otherwise in a credit line to the material. If material is not included in the article's Creative Commons licence and your intended use is not permitted by statutory regulation or exceeds the permitted use, you will need to obtain permission directly from the copyright holder. To view a copy of this licence, visit http://creativecommons.org/licenses/by/4.0/. The Creative Commons Public Domain Dedication waiver (http://creativeco mmons.org/publicdomain/zero/1.0/) applies to the data made available in this article, unless otherwise stated in a credit line to the data. 


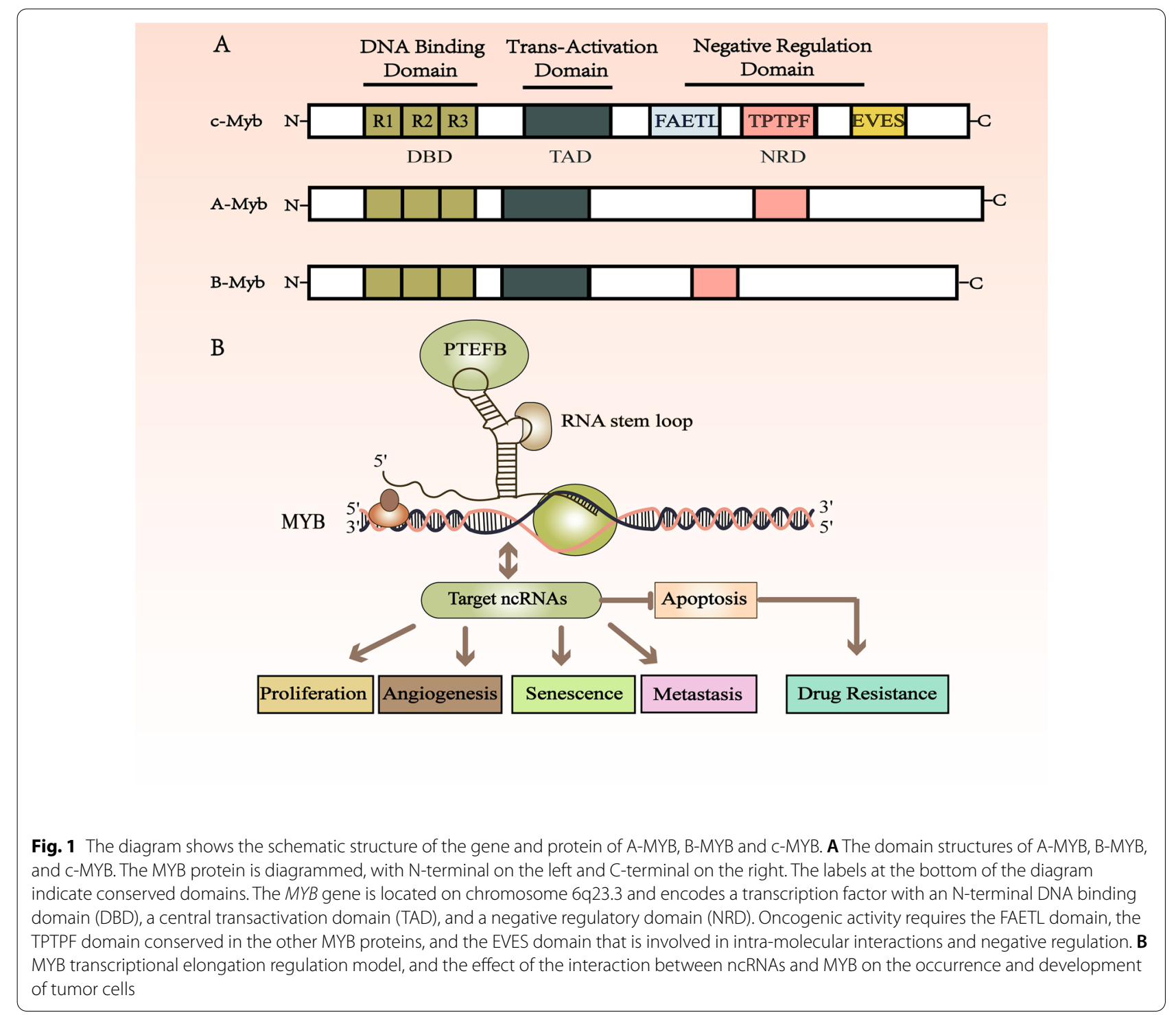

discovery of two closely related family members, MYBL1 (A-MYB) and MYBL2 (B-MYB) [6, 7]. Although their structures are similar, they may have unique biological functions. Different MYB proteins interact with distinct cofactors, and their expression is usually nonoverlapping [8-10]. A-MYB expression is limited to developing mammary glands, spermatogenic tissues, central nervous system, and T and B cells [11]. B-MYB seems to be ubiquitously expressed in normal tissues and is overexpressed in many cancers, especially leukemia, colorectal cancer, esophageal squamous cancer, bladder carcinoma and breast cancer [12-16]. The conditional inactivation of B-MYB in vivo will lead to depletion of hematopoietic stem cell (HSC) bank and a massive reduction in mature lymphocytes, erythrocytes and myelocytes [17]. C-MYB encodes a transcriptional activator that is critical for the development of the hematopoietic system [18]. A study of MYB knockout mice showed that the precise expression of MYB gene had differential effects on the development of $\mathrm{T}$ and $\mathrm{B}$ cells, bone marrow production, erythropoiesis and HSC self-renewal [7]. Numerous studies have shown that MYB overexpression can promote the growth of tumor cells [19-21]. Previous studies have shown that MYB inhibition can impair the growth, migration and invasion of cancer cells, suggesting that inhibition of MYB may be a potential cancer treatment strategy [19, $22,23]$.

MYB acts as a transcriptional activator by binding to a specific sequence, called MYB binding site (MBS) [24]. Interestingly, $M Y B$ encodes one or more proteins that 
can interact with other transcription factors such as ETS2, NFM, and CEBP [25]. Evidence suggests that there are systematic changes in the processing of RNA in cancer. These changes can be observed in the form of noncoding RNAs (ncRNAs) [26]. In the past decade, booming bioinformatics and deep sequencing technology have enabled the identification and annotation of tens of thousands of ncRNAs [27, 28]. These ncRNAs mainly include longnon-coding RNAs (lncRNAs), microRNAs (miRNAs), and cyclic RNAs (circRNAs) [29].

Over the past few years, these ncRNAs have proven to have a wide range of potential for controlling gene expression [30, 31]. LncRNAs are transcripts with a length of more than 200 nucleotides and are rapidly becoming a new type of transcript related to a variety of cellular and biological processes. The role of lncRNAs in cancer is mainly reflected in two aspects, as RNA molecules and by encoding peptides or proteins [32]. Furthermore, their abnormal expression and mutation are closely related to tumorigenesis, metastasis and tumor stage in leukemia, prostate cancer, and breast cancer [3335]. Furthermore, miRNAs disturb expression of genes or degrade messenger RNA (mRNA) translation by binding to complementary target genes [36]. MiRNAs are aberrantly expressed in a variety of tumors. The first example is miR-15a and miR-16, which provide further clues to their role in the pathogenesis of B-lymphocytic leukemia (B-CLL) [37]. CircRNAs are a class of single-stranded RNAs with closed circular structures that play significant roles in the initiation and progression of cancer [38]. Interestingly, Lee et al. found that the transcription factor (TF) c-MYB participates in the regulation of 48 miRNAs [39]. In 2009, Zhao et al. found that the c-MYB-miR-15a autoregulation feedback loop plays an important role in human hematopoiesis and confirmed that MYB plays a regulatory role in ncRNA expression [40]. In this review, we focus on the complex crosstalk between ncRNAs and MYB in the pathogenesis and development of cancers.

\section{MYB interacts with miRNAs}

In recent years, the relationship between MYB and miRNAs has been studied extensively [41]. MYB can be used as a transcriptional activator to induce up-regulation of miRNA expression. Conversely, miRNAs play a crucial role in transcriptional regulation of $M Y B$ gene expression by binding to complementary sequences in its 3 '-untranslated region (UTR) (Fig. 2).

\section{Regulation of miRNAs by MYB}

Many studies have shown that MYB participates in the regulation of miRNA expression and is involved in the pathogenesis and development of various forms of cancer

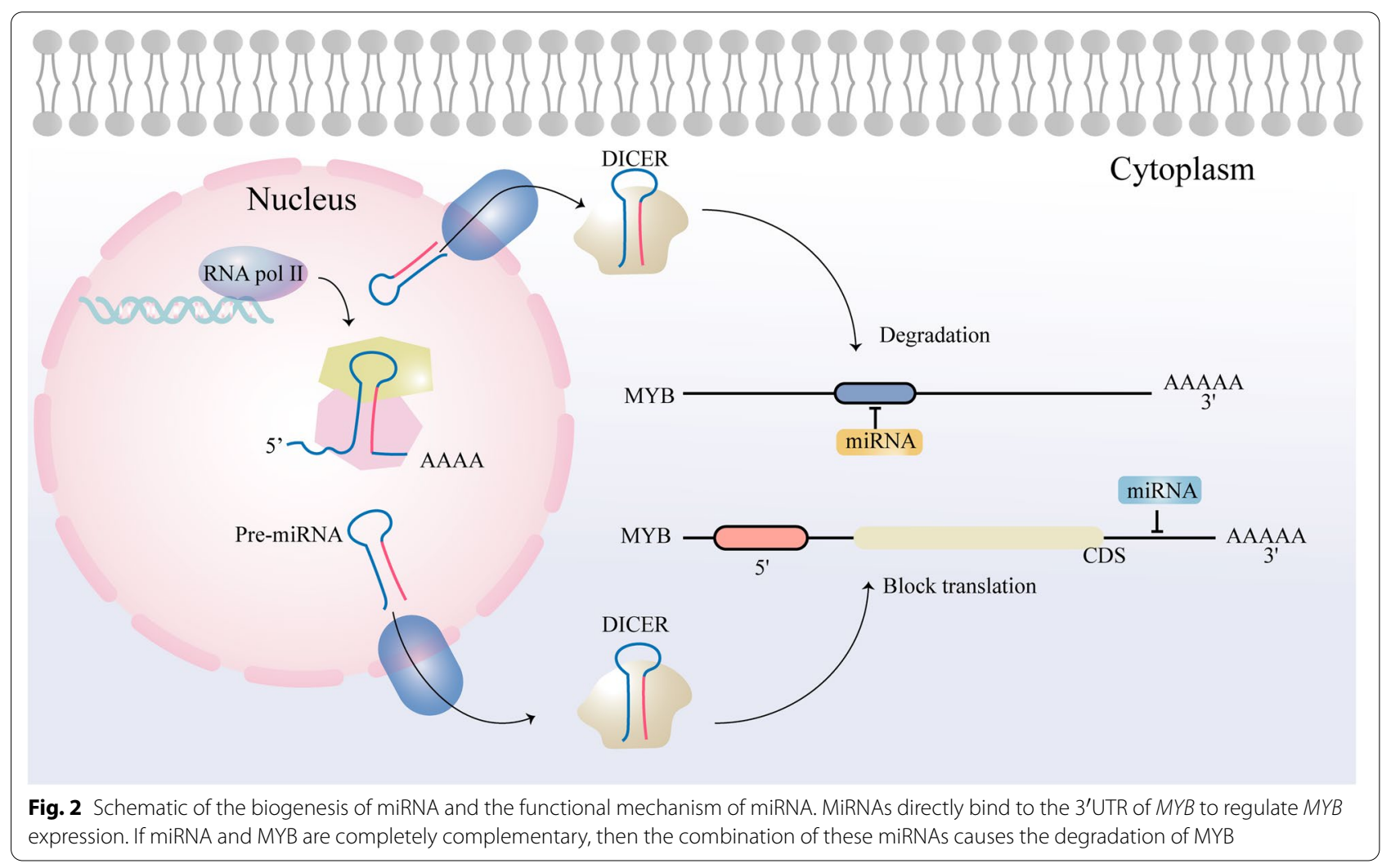


(Table 1). For example, $M Y B$ binds to MBS-C in the miR143 promoter, thereby transactivating miR-143 to affect the proliferation and differentiation of nasopharyngeal carcinoma cells [42]. MYB physically binds to the promoter of miR-155HG and activates its transcription in chronic B-CLL [43]. The proapoptotic effects of miR148a have been demonstrated in previous study [44]. MYB can transactivate BCL-2 by identifying transcription factor binding sites (TFBs) and indirectly regulate BCL-2 by inhibiting miR-148a $[45,46]$.

Notably, many MYB-regulated miRNAs affect the development of cancer by targeting certain transcription factors and tumor suppressors [47, 48]. MiR-1258 is a key target gene of MYB, and its oncogenic effect is achieved by targeting transcription factor SP-1. There is evidence that upregulated SP-1 plays a crucial role in cell proliferation and metastasis of various tumors; thus, it is considered to be a negative factor in cancer prognosis [49, 50]. In tumor cells with high $M Y B$ expression, $M Y B$ induces miR-130a expression, which inhibits the expression of tumor suppressor NDRG2 by targeting its 3'-UTR [47]. Studies have shown that MYB promotes the transcriptional activity of miR-520-h, and upregulated miR-520-h can directly downregulate membraneassociated guanylate kinase and reverse repeat member 1 (MAGI1) expression [48]. Moreover, in acute myeloid leukemia (AML), MYB expression activates miR-155 and inhibits transcription factor PU.1. The highly activated MYB/miR-155/PU.1 pathway may be involved in the pathogenesis and invasiveness of AML [51]. Interestingly, transcriptional regulators exert an enormous effect in modulating the expression of miRNA by targeting MYB. Y-box binding protein 1 (YB-1), a DNA and RNAbinding protein family member, is a multifunctional oncoprotein that plays a critical role in cell processes [52, 53]. In laryngeal squamous cell carcinoma (LSCC), YB-1 induces miR-155 expression through $M Y B$ and promotes cancer development [54].

In addition to the above unidirectional regulation of MYB and miRNA, there is also a feedback loop between MYB and miRNA. MYB transcription factors directly bind to the upstream promoter region of miR-15a, and the expression of miR-15a is caused by this binding [40]. Conversely, miR-15a can repress $M Y B$ expression. The destruction of this feedback loop may lead to abnormal MYB activity and malignant transformation [40]. The role of the miR-200 family in the treatment of breast cancer has been demonstrated [55-57]. In recent years, some studies have shown that miR-200 regulates the development of breast cancer by directly negatively regulating the expression of $M Y B$ [58]. Interestingly, $M Y B$ positively controls the expression of miR-200, but this expression depends on potent repressors and miR-200 promoter methylation [59].

Table 1 The role of miRNAs targeted by MYB in cancer development

\begin{tabular}{|c|c|c|c|c|c|c|c|}
\hline $\begin{array}{l}\text { MYB- } \\
\text { targeted } \\
\text { miRNAs }\end{array}$ & Expression & Targeting & Cellular processes & Tumor types & In vitro model & In vivo model & Refs. \\
\hline miR-520-h & Upregulated & Smad7, MAGI1 & Metastasis & RCC, EOC & $\begin{array}{l}\text { RCC cell lines (786-O, } \\
\text { A-498, OS-RC-2, } \\
\text { ACHN, CAKI-1, } \\
\text { SKRC39 and HK-2) }\end{array}$ & BALB/C nude mice & {$[48]$} \\
\hline miR-130a & Upregulated & NDRG2 & $\begin{array}{l}\text { Cell proliferation, } \\
\text { metastasis }\end{array}$ & SACC & $\begin{array}{l}\text { SACC-83, SACCLM } \\
\text { cells }\end{array}$ & $\begin{array}{l}\text { Female BALB/C-nu/ } \\
\text { nu nude mice }\end{array}$ & {$[47]$} \\
\hline miR-155 & Upregulated & PU.1 & $\begin{array}{l}\text { Cell proliferation, } \\
\text { metastasis, cell cycle }\end{array}$ & $\mathrm{AML}$ & & $\begin{array}{l}\text { PU.1/p53 double- } \\
\text { mutant mice }\end{array}$ & {$[51]$} \\
\hline miR-17-92 & Upregulated & FRZB, p21, E2F1 & Senescence & Ph-positive leukemia & $\begin{array}{l}\text { BV173, SUP-B15 and } \\
\text { K562 }\end{array}$ & $\begin{array}{l}\text { NOD/SCID gamma } \\
\text { mice }\end{array}$ & [131] \\
\hline miR-143 & Upregulated & Ras & $\begin{array}{l}\text { Cell proliferation, } \\
\text { apoptosis, DNA } \\
\text { repair, metastasis. }\end{array}$ & $\begin{array}{l}\text { Nasopharyngeal } \\
\text { carcinoma }\end{array}$ & $\begin{array}{l}\text { Human NPC cell } \\
\text { lines, c666-1, 5-8F, } \\
\text { CNE1 and CNE2 }\end{array}$ & & {$[42]$} \\
\hline miR-1258 & Downregulated & SP-1, GRB2 & $\begin{array}{l}\text { Metastasis, cell cycle, } \\
\text { senescence }\end{array}$ & OSCC, NSCLC & $\begin{array}{l}\text { OSCC cell lines } \\
\text { (SCC-9, SCC-15); } \\
\text { Human NSCLC cell } \\
\text { lines (A549, SPCA1, } \\
\text { H1299, H358, PC9, } \\
\text { 95D,16HBE); HUVEC } \\
\text { and HEK293 cells }\end{array}$ & NOD/SCID mice & {$[49,129]$} \\
\hline miR-148a & Downregulated & $\mathrm{BCL} 2$ & Apoptosis & Colorectal cancer & $\begin{array}{l}\text { RKO, LOVO, W480 } \\
\text { cells }\end{array}$ & & [111] \\
\hline
\end{tabular}




\section{MiRNAs affecting MYB expression}

Dozens of miRNAs have been described to regulate MYB expression by inhibiting its translation or degradation of its mRNA (Table 2). For example, both miR-143-3p and miR-29 negatively regulate the expression of $M Y B$ by directly binding to the $3^{\prime} \mathrm{UTR}$ of $M Y B[60,61]$. Many miRNAs show reduced levels in cancer, the inhibition of $M Y B$ by these miRNAs is removed, and the expression of $M Y B$ is upregulated. Therefore, the ordinarily high MYB level may be due to the decreased expression of tumor suppressor miRNAs, such as miR-96, miR-34a, miR-15a/16, miR-193b-3p, miR-548c-3p and miR-155 [62-69].

MYB enhances erythropoiesis and miR-150 affects both $M Y B$ mRNA stability and translation efficiency [70]. $M Y B$, a top predicted target of miR-150, has been fully proved. MiR-150 can induce EBV-positive BL differentiation by targeting $M Y B$ [71]. Moreover, miR-150 also plays a vital role in B cell development and differentiation of other hematopoietic cell lines. In chronic myeloid leukemia (CML), miR-150 can target MYB and inhibit the expression of a series of oncogenes, thus suppressing the proliferation of CML cells [72]. In human colorectal cancer, miR-150 also plays a tumor-suppressive role by targeting $M Y B$ [73]. By further focusing on the role of miRNA, new treatment strategies could be found to overcome cancers associated with elevated MYB.

\section{MYB interacts with IncRNAs}

Abnormal expression of lncRNAs may contribute to the occurrence and development of a variety of cancers, and is partly regulated by the transcription factor MYB [74]. The expression of MYB in cancer is regulated at the level of alternative splicing, transcription, translation. Some lncRNAs can function during MYB regulation $[75,76]$.

\section{Regulation of IncRNAs by MYB}

In eukaryotic cells, it is known that multifunctional MYB transcription factors regulate the expression of targeted genes by binding to specific DNA sequences [77]. The '-231 -222' bp region in the promoter of UCA1 is the main binding site of MYB transcription factor in hepatocellular carcinoma cells (HCC). The link between TFBs and MYB in $\mathrm{HCC}$ was reduced by downregulating the expression of the coactivator staphylococcal nuclease and 1-containing Tudor domain (SND1) [74]. Therefore, it is

Table 2 The role of miRNAs targeting MYB in a variety of cancers

\begin{tabular}{|c|c|c|c|c|c|}
\hline Targeting MYB & Cellular processes & Tumor types & In vitro model & In vivo model & Refs. \\
\hline miR-200 & Cell proliferation, resistance & Breast cancer & MCF-7, T47D cells & & {$[58]$} \\
\hline miR-143-3p & Cell proliferation, apoptosis & Breast cancer & $\begin{array}{l}\text { Normal breast cell line MCF- } \\
\text { 10A, breast cancer cell line } \\
\text { MDA-MB-435 }\end{array}$ & & {$[60]$} \\
\hline miR-195 & $\begin{array}{l}\text { Cell proliferation, apoptosis, } \\
\text { metastasis }\end{array}$ & NSCLC & A549, H129 & Female athymic nude mice & {$[100]$} \\
\hline miR-424 & $\begin{array}{l}\text { Cell proliferation angiogenesis, } \\
\text { metastasis }\end{array}$ & Ovarian cancer & $\begin{array}{l}\text { The normal human ovarian epi- } \\
\text { thelial cell line HOSEpiC, human } \\
\text { ovarian cancer cell lines (SKOV- } \\
\text { 3, HO8910, A2780), HUVECS }\end{array}$ & $\begin{array}{l}\text { Immunodeficient female nude } \\
\text { mice }\end{array}$ & [121] \\
\hline miR-548c-3p & Cell proliferation, metastasis & Glioma & $\begin{array}{l}\text { The human glioma T98G, U87, } \\
\text { U251, HEK-293 cells (CRL-1573) }\end{array}$ & & [68] \\
\hline hsa-miR-495 & Cell proliferation, metastasis & Glioma & $\begin{array}{l}\text { Human glioma cell lines (A172, } \\
\text { U87, U251, U373) }\end{array}$ & & [69] \\
\hline miR-150 & $\begin{array}{l}\text { Cell proliferation, apoptosis, } \\
\text { cell cycle }\end{array}$ & $\begin{array}{l}\text { Colorectal cancer, } \\
\text { liver cancer, CML }\end{array}$ & $\begin{array}{l}\text { K562, Meg-01, KCL-22, HL-60, } \\
\text { KG-1; colorectal cancer cell line }\end{array}$ & Nude mice & {$[72,73,113]$} \\
\hline miR-130a & Angiogenesis & GC & $\begin{array}{l}\text { The human gastric cell line } \\
\text { SGC7901, the human gastric } \\
\text { mucosal epithelial cell line } \\
\text { GES-1 }\end{array}$ & $\begin{array}{l}\text { Female nude mice (BALB/C-nu, } \\
6-8 \text { weeks) }\end{array}$ & [118] \\
\hline miR-155 & Angiogenesis & GC & $\begin{array}{l}\text { Human SGC-7901 cells, } \\
\text { HEK293T cells, HUVEC cell }\end{array}$ & Male nude mice (BALB/C-nu) & [120] \\
\hline miR-29 & Cell cycle & Breast cancer & $\begin{array}{l}\text { T-47D, MDA-MB- } 453, \text { MCF-7, } \\
\text { MCF- } 10 \text { A cells }\end{array}$ & & {$[61]$} \\
\hline miR-193b-3p & Cell proliferation & T-ALL & T-ALL cell lines & T-ALL patient samples & {$[67]$} \\
\hline miR-103a & Cell proliferation, metastasis & GC & $\begin{array}{l}\text { MKN-45, HGC-27, MGC-803, } \\
\text { SGC-7901, GES }\end{array}$ & & {$[30]$} \\
\hline
\end{tabular}

CML, chronic myeloid leukemia; GC, gastric cancer; HEK, human embryonic kidney; HUVECs, human umbilical vein endothelial cells; MDA, malonaldehyde; NSCLC, non-small cell lung cancer; T-ALL, T cell acute lymphoblastic leukemia; PHFG, primary human fetal glial 
possible that regulatory effect of SND1-MYB complex can upregulate expression of IncRNA UCA1, thereby curbing the apoptosis levels of HCC cells [74].

\section{IncRNAs affecting MYB expression}

MYB deregulation has been associated with aggressive behavior in human malignancies [6]. Four lncRNAs promote the expression of $M Y B$ by acting as sponges of miRNAs (Table 3). The expression of LINC01287 in HCC cell lines and tissues was elevated [78]. LINC01287 plays a role as a competitive endogenous RNA (ceRNA) and negatively regulates the expression of miR-298 thus promoting the expression of MYB. High expression of MYB may affect cell cycle progression and promote an epithelial-mesenchymal transition (EMT) phenotype [78]. LncRNA zinc finger antisense 1 (ZFAS1) and lncRNA MAF BZIP transcription factor $G$ antisense RNA 1 (MAFG-AS1) have been reported to be oncogenic factors in some malignancies [79, 80]. ZFAS1 and MAFGAS1 act as molecular sponges for miR-150, resulting in downregulation of miR-150 and upregulation of $M Y B$ in cancers [75, 81]. High expression of lncRNA AK023391, is positively correlated with poor survival of patients with gastric cancer (GC) [82]. A study showed that cytoplasmic AK023391 is a key mediator of signal transduction in GC. IncRNA AK023391 upregulates MYB by activating the PI3K/Akt pathway, promoting GC tumorigenesis and progression [82]. Furthermore, IncRNA MALAT1 actively regulates the expression of oncogenic transcription factor MYB (Fig. 3). During the cell cycle, dynamic changes in MALAT1 levels may titrate the intracellular SR protein pool and its association with pre-mRNAs, thereby affecting the alternative splicing, stability and expression of $M Y B$ [76]. Interestingly, lncRNA DRHC inhibits cell proliferation, migration and invasion by binding to MYBBP1A and inhibiting $M Y B$, which controls MAPK signal transduction by directly regulating the transcription of genes encoding the negative regulator SPRY2 [83]. LOC102724169 suppresses the expression of MYB in ovarian cancer with chronic stress (OCCS) by weakening PI3K/Akt signal transduction, which enhances the chemosensitivity to cisplatin and plays an antitumor role in OCCS [84]. A new study shows the carcinogenic activity of LncRNA NTT is attributed to the activation of MYB by interacting with activated complexes. The results suggest that NTT may be a new therapeutic target for the treatment of liver cancer [85].

In addition, to the more direct regulation of MYB by lncRNAs as described above, a more complex feedback loop between MYB and lncRNAs has been identified. SNHG10 eliminated the inhibitory effect of miR-150-5p on $M Y B$, resulting in increased $M Y B$ expression [86]. Moreover, SNHG10 promotes the expression of RPL4, based on the direct interaction between RPL4 and $M Y B$, which leads to an increase in $M Y B$ functional activity [86]. Reciprocally, overexpression and overactivation of $M Y B$ enhance the expression of SNHG10 and SCARNA13 by binding to the promoter region of SNHG10 [86]. Collectively, SNHG10 regulates the expression of SCARNA13 through the miR-150-5p/ RPL4-MYB positive feedback loop to facilitate the development and progression of HCC [86].

\section{MYB interacts with circRNAs}

CircRNAs are a class of ncRNA molecules without a 5 '-end cap and a 3 '-end poly (A) tail [87], and they are formed by covalent bonds with a circular structure [38]. They are widely diverse endogenous RNA molecules that regulate gene expression in eukaryotic cells [88]. Functionally, circRNAs act as transcriptional regulators to control the expression of host genes [89, 90]. CircRNAs are closely associated with human diseases, especially cancers, and may be better biomarkers due to their abundance and stability [91-94]. Recent studies have shown that circRNAs are rich in miRNA binding sites and act as miRNA sponges in cells, thereby relieving the inhibitory effect of miRNAs on their target genes and thus increasing their expression [95] (Fig. 3). Interestingly, the differential expression circRNA back-spliced from $M Y B$ gene can act as a sponge of miRNA and play a vital role in diseases [96]. Among patients with colorectal cancer, the overexpression of MYB promotes the transcription of circHIPK3 and circHIPK3 has oncogenic functions by sponging miR-7 [97]. Moreover, hsa_circ_0015326 sponges miR-127-3p to regulate MYB signaling, which is closely related to the occurrence and development of ovarian cancer [98]. In summary, hsa_circ_0015326 positively regulates MYB signaling and acts as a tumorpromoting factor; thus, its downregulation could be a potential therapeutic approach [98].

\section{Role of non-coding RNAs and MYB in cancers}

Multiple ncRNAs play a crucial role in cell processes and tumorigenesis. The interaction between ncRNAs and MYB is involved in tumor cell proliferation, apoptosis, angiogenesis, metastasis, senescence, and drug resistance (Fig. 1).

\section{Proliferation}

The unlimited proliferation of cancer cells contributes to their malignant phenotype and affects the prognosis of patients. Increasing evidence suggests that MYB has survival-promoting functions. Some miRNAs impede the function of MYB, thereby inhibiting cancer cell proliferation (Fig. 4). Matrix metalloproteinases (MMPs) belong to the protease family and have been shown to play a key 


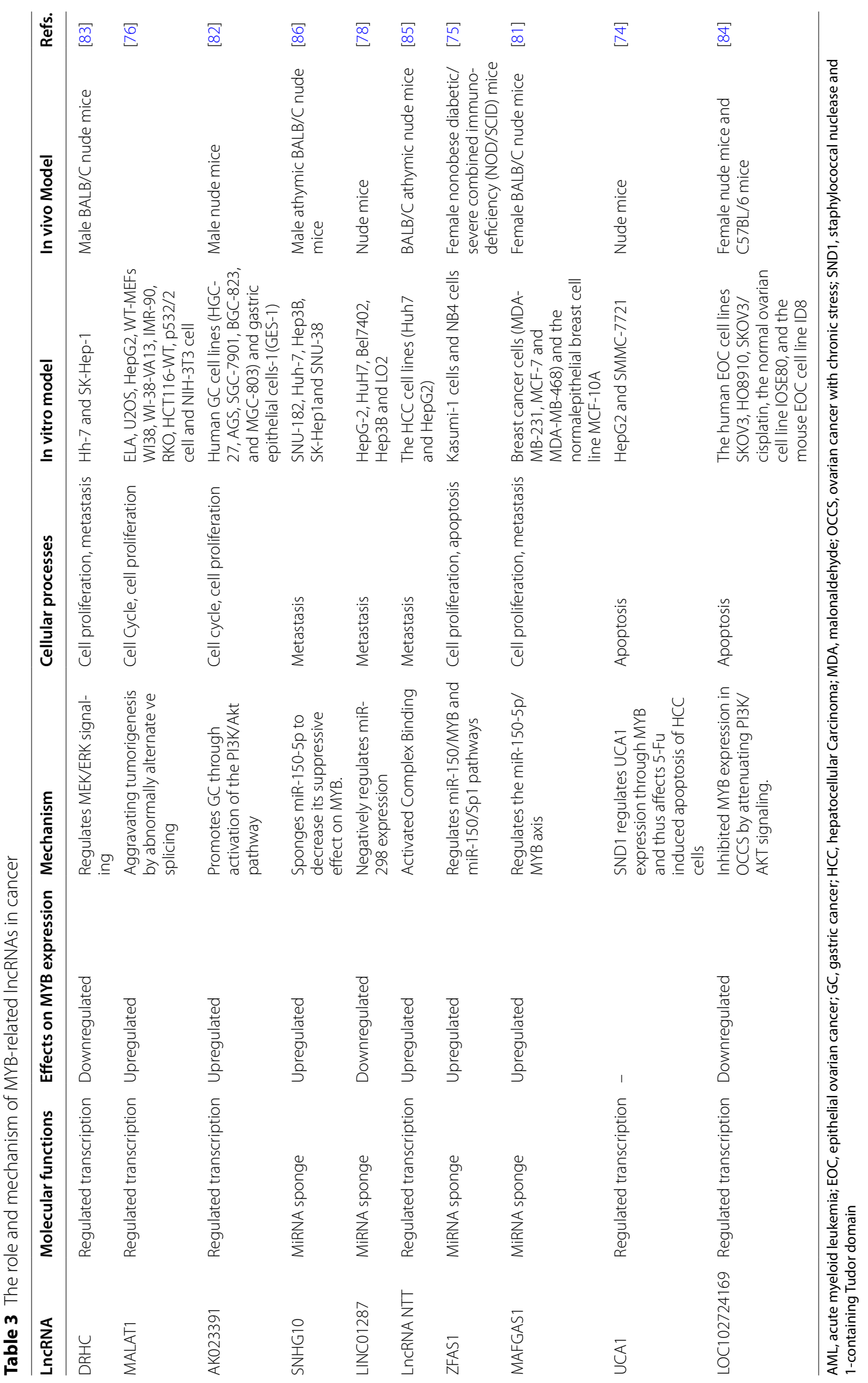




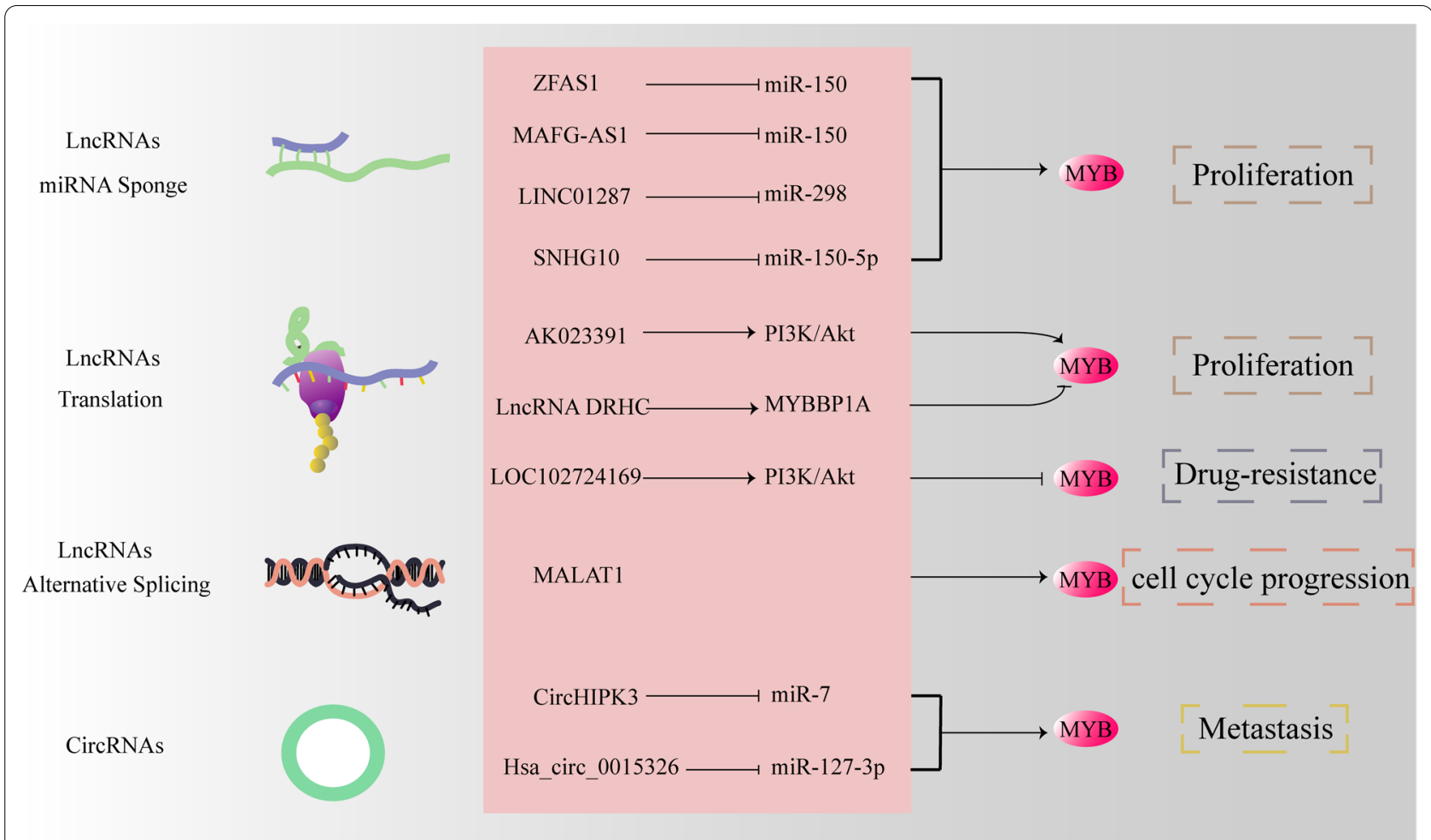

Fig. 3 LncRNAs and circRNAs promote the expression of MYB through multiple signaling pathways. Some IncRNAs and circRNAs act as molecular sponges and bind to miRNAs, thereby upregulating the level of miRNA target genes. MALAT1 modulates the expression of cell cycle genes by regulating pre-mRNA alternative splicing

role in tissue remodeling and supporting cancer development [99]. In non-small-cell lung cancer (NSCLC), miR195 directly targets MYB 3'UTR and negatively regulates its expression, thereby regulating the proliferation and metastasis of tumor cells [100]. In addition, $M Y B$ gene deletion can inhibit the expression of BCL2 and MMP-9 [101]. Meanwhile, MMP-1 and MMP-9 were downregulated along with BCL2 and CCNE1 in A549 and H1299 cells transfected with miR-195. In general, this suggests that miR-195 at least partially reduces the expression of BCL2 and MMP-9 through MYB [100]. Recent studies indicate that MYB plays an essential role in the development and progression of GC [102]. MYB was identified as the functional downstream target of miR-103a, and its ectopic expression partially reversed the inhibition of cell proliferation and invasion. Therefore, miR-103a regulates the development of tumors by regulating $M Y B$ [30, 103]. Many studies have confirmed that miR-150 regulates MYB and affects the proliferation of various types of tumor cells [71, 104, 105]. Mitogen-activated protein kinase (MAPK) signal transduction is a highly conserved signaling pathway involved in a variety of biological events, including metabolic reprogramming, cell proliferation, survival, and differentiation. Mutations in key molecules involved in MAPK/ERK signaling and maladjustment of this pathway are common events in many human malignancies [106]. MAPKs in mammals include JNK, p38 and ERK. MAPK/ERK signaling pathway plays a key role in tumorigenesis and development by promoting cell proliferation and metastasis. In hepatocellular carcinoma, lncRNA DRHC interacts with MYBBP1A and regulates the proliferation of hepatoma cells by regulating MEK/ERK signaling through $M Y B$. However, the exact mechanism of lncRNA DRHC/MYBBP1a/ MYB is not clear [83].

\section{Apoptosis}

Apoptosis plays a vital role in maintaining tissue homeostasis, and imbalance of the apoptosis pathway is considered a critical step in tumorigenesis [107]. Many studies have found that the interaction between MYB and ncRNAs can regulate tumor cell apoptosis (Fig. 4). MYB is involved in cancer progression and has become an important target of various miRNAs, such as miR-423-5p and miR-143-3p [60, 108]. In colorectal cancer, knocking down MYB can promote the expression of miR-148a, and knockout of $M Y B$ can also partially induce apoptosis of cancer cell lines [46]. More interestingly, the expression 


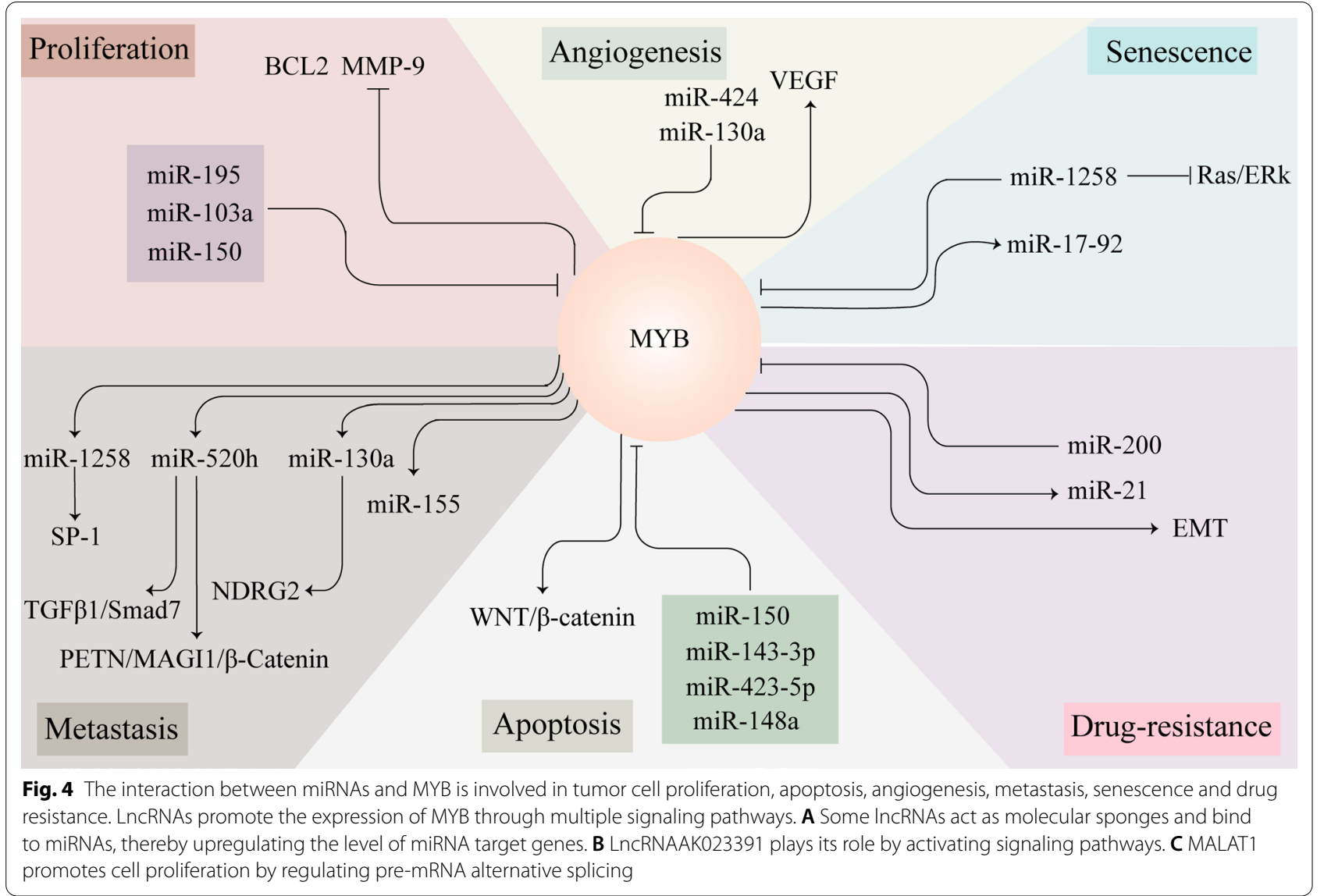

of miR-30b-5p is significantly downregulated in medulloblastoma (MB) cells. miR-30b-5p inhibits MB progression by targeting the expression of MYB [109]. A study showed that melatonin inhibits the expression of miR155 , thus inhibiting the proliferation, migration and invasion of glioma cells. It has been suggested that melatonin may be a therapeutic strategy for MYB-miRNA-induced glioma [110]. A negative correlation between MYB and miR-143-3p expression was found in breast cancer tissues and cells. More importantly, MYB is involved in regulating the proliferation and apoptosis of breast cancer cells [60]. Antisense miR-148a inhibitors can restore down-regulated MYB-induced apoptosis [46]. To sum up, MYB seems to be the key regulator of miR-148a promoting apoptosis in colorectal cancer cells [111]. In the case of glioblastoma, some studies have illustrated that miR-148a acts as a negative risk factor. Upregulated miR148a could accelerate malignant process and is negatively correlated with the survival rate [111]. Some studies have proved that isomorphic diffuse gliomas have MYB/ MYBL1 changes, thus MYB plays an important role in the development of glioblastoma [112]. We speculate that there may be a close relationship between miR-148a and MYB in gliomas. A negative correlation between MYB and miR-143-3p expression was found in breast cancer tissues and cells. More importantly, MYB is involved in regulating the proliferation and apoptosis of breast cancer cells [60]. The overexpression of miR-150 increases the apoptosis of $\mathrm{CD}_{133^{+}}$hepatoma cells. MiR-150 inhibits the expression of $M Y B$, leading to changes in several key proteins related to the cell cycle and cell survival, including cyclin D1 and BCL-2 [113]. SND1 are evolutionarily conserved proteins that exist in eukaryotic cells from protozoa to mammals. SND1 is becoming increasingly important because it is overexpressed in invasive cancer cells and a variety of primary tumors. Currently, it is considered to be a sign of malignancy [114]. Studies have shown that MYB protein, which binds SND1 protein, may act as a transcription factor of lncRNA UCA1 in vitro. In addition, SND1 may upregulate the expression of lncRNA UCA1 by acting as a coactivator of MYB, thus affecting the apoptosis of HCCs [74].

\section{Angiogenesis}

Angiogenesis plays an important role in the development and metastasis of tumors, and inhibition of this process will prevent the development and diffusion of tumor tissues $[115,116]$. Given the critical position of angiogenesis 
in tumor formation and development, it is of great significance to find new anti-vascular targets. A great deal of evidence indicates that the interaction between ncRNAs and MYB can affect angiogenesis in numerous tumors. As a transcription factor, MYB is related to various intracellular biological behaviors and is closely related to the process of angiogenesis (Fig. 4) [117]. MYB is the direct target of miR-130a. Cancer-derived exosomes carry miR130a from GC cells to vascular cells by targeting $M Y B$ to promote angiogenesis and tumor growth [118]. Vascular endothelial growth factor A (VEGF) is the primary mediator of angiogenesis, and VEGF directly contributes to targeting tumor cell growth and metastasis [119]. In addition, other studies have found a negative correlation between the expression of miR-155 and MYB in gastric cancer [120]. More importantly, experiments have shown that MSCs can transport miR-424 to ovarian cancer cells to target MYB to further inhibit the expression of VEGF and the proliferation, migration and tube formation of endothelial cells, to block angiogenesis [121].

\section{Metastasis}

Metastasis is known to be the leading cause of cancerrelated deaths and is a considerable challenge in cancer treatment [122, 123]. In addition to cooperating with protein-coding promoters, MYB also enhances the activity of ncRNA promoters to facilitate cancer initiation and metastasis [48]. MAGI1 is a member of a protein family, that plays an important role in coupling the extracellular environment with intracellular signaling pathways and the cytoskeleton at synapses and tight junctions. One piece of evidence confirmed the key role of MAGI1 in regulating cell-cell contact, which is always destroyed in tumor progression and related to invasiveness and metastasis [124]. In recent years, studies have shown that MAGI1 can be directly targeted by miR-520-h in renal cell carcinoma (RCC) cells [48]. At the same time, MYB promotes the transcriptional activity of miR-520-h by binding to the RCC promoter to regulate MAGI1 expression, and the overexpression or knockout of MAGI1 regulates PETN/MAGI1/ $\beta$-Catenin and significantly affects the invasion and migration of human renal cell carcinoma cells [48]. In epithelial ovarian cancer (EOC), miR-520-h promotes EOC progression by activating TGF- $\beta 1 / \mathrm{Smad} 7$ signal transduction pathway. Overexpression of Smad7 attenuated the oncogenic effect of miR-520-h [125]. More importantly, in EOC, TGF- $\beta 1$ increases the expression of miR-520-h by upregulating its upstream transcription factor MYB [48, 125]. NDRG2 is a critical anticancer gene in salivary adenoid cystic carcinoma (SACC), which contributes to inhibiting cell proliferation and metastasis of SACC. A study has confirmed that MYB is a crucial driver by which SACC overexpresses miR-130a, thereby inducing downregulation of NDRG2 [47]. In addition, miR-1258 has been found to have an inhibitory effect on a variety of cancers. In oral squamous cell carcinoma (OSCC), MYB inhibits miR-1258 by directly binding to the miR-1258 promoter [49]. Dysregulated miR-1258 promotes the expression of SP-1 protein, which contributes to the development of OSCC [49]. Importantly, there is evidence that SP-1 plays a role in cancer progression, invasion and metastasis. SP-1 can promote cell proliferation by accelerating the cell cycle from $\mathrm{G} 1$ to $\mathrm{S}$ phase [126, 127]. In human LSCC, YB-1 transcription factors promote the invasion and migration of cancer cells through MYB-induced miR-155 expression [54]. In addition, the abnormal expression of YB-1/MYB/miR155 promotes the progression of laryngeal carcinoma and is related to poor prognosis [54]. Therefore, YB-1 can be considered as a potential prognostic and therapeutic target for patients with laryngeal cancer. Moreover, MYB upregulates circRNAs at the transcriptional level, such as circHIPK3, which acts as a novel oncogenic circRNA by sponging miR-7. MYB inhibits the expression of circHIPK3, and the metastasis of cancer cells can be controlled [97]. In summary, the above studies show that it is urgent to deeply understand the complex relationship between MYB and ncRNAs. This is very important for the metastasis of cancer cells in vivo and an important strategy to control the development of cancer cells.

\section{Senescence}

Growing evidence suggests that MYB is a potential candidate for the regulation of senescence, and inhibition of MYB expression plays an essential role in the growth arrest of senescence (Fig. 4) [128]. MYB inhibits the expression of miR-1258. When MYB is suppressed, the overexpression of miR-1258 inhibits the expression of GRB2 and then inactivates the carcinogenic pathway of Ras/ERK, which then induces senescence and apoptosis of tumor cells $[49,129]$. Moreover, miR-17-92 promotes tumorigenesis by antagonizing oncogene-induced senescence [130]. MYB significantly adjust the expression of miR-17-92 targets such as p21, a key effector of senescence. When MYB is silenced, the survival of cells can be suppressed [131].

\section{Drug-resistance}

Drug resistance is another major clinical challenge in cancer treatment. In breast cancer, MYB induces EMT and significantly increases tamoxifen resistance. Given the ability of miR-200 to control gene expression, it has emerged as an important role in response to anticancer therapies, particularly in the development of drug resistance (Fig. 4). Experiments have shown that miR200 inhibits the expression of MYB, reversing the drug 
resistance of cancer cells to tamoxifen. This might be the result of miR-200-MYB regulating EMT [58]. Interestingly, MYB can activate the expression of miR-200 through a transcriptional, binding-dependent mechanism. It may also be related to drug resistance [59]. Moreover, in ovarian cancer, high MYB expression can cause tumor cells to resist cisplatin. Silencing $M Y B$ reduced the miR-21 level and EMT, which reverses cisplatin resistance [132].

\section{Potential clinical application of MYB and noncoding RNAs in cancer}

Due to the increasing knowledge about the biology and function of MYB and ncRNAs and the emergence of new treatment opportunities, some drugs can make use of a variety of mechanisms, directly and indirectly, and affect the relationship between MYB and ncRNAs in different ways, to inhibit the growth and metastasis of tumor cells $[110,133]$.

\section{Targeting MYB}

In recent years, several approaches have been attempted to inhibit abnormal MYB expression in cancer cells. The initial attempt was to use RNA interference (RNAi) to inhibit $M Y B$. In a mouse model of MLL-AF9 leukemia, MYB specific shRNA effectively silenced MYB and showed that its inhibition could eradicate invasive leukemia in vivo without affecting normal myelopoiesis [134]. Another study found that a MYB DNA vaccine in combination with an anti-PD-1 antibody or low dose cyclophosphamide effectively extended survival of colorectal cancer (CRC) bearing mice [135]. Moreover, important coactivators and degradation regulators of MYB have been investigated as therapeutic targets. Recently, mebendazole has been shown to effectively inhibit in vivo progression of AML by interfering with the heat shock protein 70 (HSP70) chaperone system and inducing MYB degradation by proteasome [136]. Many studies have shown that melatonin has significant apoptotic, angiogenesis, antitumor and antiproliferation effects on many kinds of tumor cells [137]. In gliomas, melatonin may affect the expression of MYB to inhibit miR-155, thus inhibiting the proliferation, migration and invasion of glioma cells. Therefore, correlation between melatonin and $\mathrm{MYB} / \mathrm{miR}-155$ may provide a new strategy for the treatment of human gliomas [110].

\section{Targeting ncRNAs}

In fact, in addition to our above treatment strategies for MYB, ncRNAs mentioned in this review can also be used as a target for cancer treatment. For example, antisense miR-155 molecule cobomarsen (MRG-106) uses LNAmodified antisense oligodeoxynucleotides to inhibit
miR-155 in the treatment of T-cell lymphoma, which means that oligonucleotides composed of LNA may be a valuable ncRNAs detection tool in cancer diagnosis and prognosis. A Phase I clinical trial of cobomarsen was launched in 2016 [138]. A study showed that targeted delivery of miR-34a mimics using lipid emulsions significantly inhibited cancer progression in a xenograft mouse model of colon cancer [139]. Therefore, MRX34, a miR-34a liposome injection, entered a phase I clinical trial in 2013. Although the experiment was ultimately terminated, the development of MRX34 showed feasibility [140]. Moreover, ginkgetin is a natural nontoxic biflavone, that has been proven to have anti-cancer, antiinflammatory, anti-microbial, anti-adipogenesis and neuroprotective activities [141]. Ginkgetin can combat cancer progression by blocking cell cycle, inducing apoptosis, stimulating autophagy and targeting many dysfunctional signaling pathways [141]. In colon cancer, ginkgo flavonoids regulate the expression of miR-34a to regulate the expression of MYB, which can induce G2 phase arrest and apoptosis of colorectal cancer cells [133]. In summary, ncRNAs targeting MYB show great hope in preliminary studies. A better understanding of MYB and its regulation of ncRNA activity and expression to select effective inhibitors should help to improve the survival rate of patients with MYB-related tumors.

\section{Conclusion}

There are several mechanisms to activate MYB in human cancer. In general, these mechanisms will lead to higher levels or more transcriptionally active MYB, and to persistent expression. The ability of MYB to block differentiation seems to be responsible for this sustained expression. Moreover, tumor cells are "addicted" to the higher level of MYB. Therefore, MYB transcription factor is a suitable target for tumor therapy. However, the lack of effective MYB-specific inhibitors has been a significant problem in clinical studies. The development of MYB-targeted regulation will help improve survival in patients with MYB-related tumors. MYB is also regulated by multilayered network of ncRNAs with multiple ncRNAs. NcRNAs act as modulators of MYB, and they regulate MYB at the transcription, translation, protein stability, and functional levels through various mechanisms. Reciprocally, ncRNAs can also act as effectors of MYB and even form feedback loops with MYB. Furthermore, given the known tissue specificity of ncRNAs expression, the involvement of ncRNAs as MYB cofactors may become a new potential target to control MYB expression. This method of identifying the addiction of oncogenes to cancer and aiming to control the regulatory mechanisms driving oncogene expression may be a new approach of anticancer drugs. Moreover, the 
ncRNA-MYB coregulatory network brings a systematic and enlightening point of view for the regulation of gene expression in cancer prognosis. Evidence suggests that treatment for miRNA and TFs has a broader effect compared with treatment for a single gene. The combination of miRNA mimics and inhibitors targeting the same oncogene can produce synergy, prolong the effective treatment window and may bring better therapeutic effects. Importantly, synergy can produce similar or better efficacy at lower inhibitor dosages, help to improve the specificity of combination therapy and reduce the toxicity and side effects at higher doses [142]. Therefore, further research is needed to develop effective therapeutic interventions aimed at inhibiting MYB-related oncogene signaling in tumors while minimizing the risk to patients.

\begin{abstract}
Abbreviations
V-MYB: Virus MYB; AMV: Avian myeloblastosis virus; DBD: DNA-binging domain; NRD: Negative regulatory domain; TAD: Transactivation domain; c-MYB: Cellular MYB; HSC: Hematopoietic stem cell; MBS: MYB binding site; ncRNAs: Noncoding RNA; LncRNA: Long-non-coding RNA; miRNA: MicroRNA circRNA: Cyclic RNA; mRNA: Messenger RNA; B-CLL: B-lymphocytic leukemia; TF: Transcription factor; UTR: Untranslated region; TFBs: Transcription factor binding sites; MAGI1: Membrane-associated guanylate kinase and reverse repeat member 1; AML: Acute myeloid leukemia; YB-1:Y-box binding protein 1; LSCC: Laryngeal squamous cell carcinoma; CML: Chronic myeloid leukemia; HCC: Hepatocellular carcinoma cells; SND1: Staphylococcal nuclease and 1-containing Tudor domain; ceRNA: Competitive endogenous RNA; EMT: Epithelial-mesenchymal transition; ZFAS1: Zinc finger antisense 1; MAFG-AS1: MAF BZIP transcription factor G antisense RNA 1; GC: Gastric cancer; OCCS: Ovarian cancer with chronic stress; MMPs: Matrix metalloproteinases; NSCLC: Non-small-cell lung cancer; MAPK: Mitogen-activated protein kinase; MB Medulloblastoma; VEGF: Vascular endothelial growth factor A; RCC: Renal cell carcinoma; EOC: Epithelial ovarian cancer; SACC: Salivary adenoid cystic carcinoma; OSCC: Oral squamous cell carcinoma; RNAi: RNA interference; CRC: Colorectal cancer; HSP70: Heat shock protein 70.
\end{abstract}

\section{Acknowledgements}

Not applicable.

\section{Authors' contributions}

JZ designed the manuscript. HD and SW wrote a complete draft and first version of the manuscript. LL, YW, SY, ZL, FW, and JZ edited and reviewed the manuscript. All authors approved final the version and contributed to the principal layout of the article. All authors read and approved the final manuscript.

\section{Funding}

This article represents an independent research project part funded by the National Natural Science Foundation of China (No. 82170138, 81870105 and 81770107), Scientific Research Fund Project of Hunan Provincial Health Commission (No. 20201921), National Key Research and Development Program of China (2018YFA0107800) and Natural Science Foundation of Hunan Province (No. 2021JJ30022)

Availability of data and materials

Not applicable.

\section{Declarations}

Ethics approval and consent to participate Not applicable.

\section{Consent for publication}

All authors agree with the final version of the manuscript and give their consent for its publication.

\section{Competing interests}

The authors declare that they have no competing interests.

\section{Author details}

${ }^{1}$ The First Affiliated Hospital, Department of Rheumatology, Hengyang Medical School, University of South China, Hengyang 421001, Hunan, China. ${ }^{2}$ Hunan Province Key Laboratory of Basic and Applied Hematology, Molecular Biology Research Center \& Center for Medical Genetics, School of Life Sciences, Central South University, Changsha 410078, Hunan, China. ${ }^{3}$ Department of Clinical Laboratory, Shenzhen Traditional Chinese Medicine Hospital, Shenzhen 518033, Guangdong, China.

Received: 16 September 2021 Accepted: 24 November 2021

Published online: 07 December 2021

\section{References}

1. Zhou Y, Ness SA. Myb proteins: angels and demons in normal and transformed cells. Front Biosci. 2011:16:1109-31.

2. Urbanek P, Dvorak M, Bartunek P, Pecenka V, Paces V, Travnicek M. Nucleotide sequence of chicken myb proto-oncogene promoter region: detection of an evolutionarily conserved element. Nucleic Acids Res. 1988;16(24):11521-30.

3. Lipsick JS, Manak J, Mitiku N, Chen CK, Fogarty P, Guthrie E. Functional evolution of the Myb oncogene family. Blood Cells Mol Dis. 2001;27(2):456-8.

4. Zhou YE, O'Rourke JP, Edwards JS, Ness SA. Single molecule analysis of c-myb alternative splicing reveals novel classifiers for precursor B-ALL. PLoS ONE. 2011;6(8): e22880.

5. Brill LB 2nd, Kanner WA, Fehr A, Andren Y, Moskaluk CA, Loning T, Stenman G, Frierson HF Jr. Analysis of MYB expression and MYB-NFIB gene fusions in adenoid cystic carcinoma and other salivary neoplasms. Mod Pathol. 2011;24(9):1169-76.

6. Ciciro Y, Sala A. MYB oncoproteins: emerging players and potential therapeutic targets in human cancer. Oncogenesis. 2021;10(2):19.

7. Liu X, Xu Y, Han L, Yi Y. Reassessing the potential of Myb-targeted anticancer therapy. J Cancer. 2018;9(7):1259-66.

8. O'Rourke JP, Ness SA. Alternative RNA splicing produces multiple forms of c-Myb with unique transcriptional activities. Mol Cell Biol. 2008;28(6):2091-101.

9. Ramsay RG, Gonda TJ. MYB function in normal and cancer cells. Nat Rev Cancer. 2008;8(7):523-34.

10. Rushton JJ, Davis LM, Lei W, Mo X, Leutz A, Ness SA. Distinct changes in gene expression induced by A-Myb B-Myb and c-Myb proteins. Oncogene. 2003;22(2):308-13.

11. Golay J, Luppi M, Songia S, Palvarini C, Lombardi L, Aiello A, Delia D, Lam $\mathrm{K}$, Crawford DH, Biondi A, et al. Expression of A-myb, but not c-myb and B-myb, is restricted to Burkitt's lymphoma, slg + B-acute lymphoblastic leukemia, and a subset of chronic lymphocytic leukemias. Blood. 1996;87(5):1900-11.

12. Fuster O, Llop M, Dolz S, Garcia P, Such E, Ibanez M, Luna I, Gomez I, Lopez M, Cervera J, et al. Adverse prognostic value of MYBL2 overexpression and association with microRNA-30 family in acute myeloid leukemia patients. Leuk Res. 2013;37(12):1690-6.

13. Qin HD, Liao XY, Chen YB, Huang SY, Xue WQ, Li FF, Ge XS, Liu DQ, Cai Q, Long J, et al. Genomic characterization of esophageal squamous cell carcinoma reveals critical genes underlying tumorigenesis and poor prognosis. Am J Hum Genet. 2016;98(4):709-27.

14. Nord H, Segersten U, Sandgren J, Wester K, Busch C, Menzel U, Komorowski J, Dumanski JP, Malmstrom PU, de Stahl TD. Focal amplifications are associated with high grade and recurrences in stage Ta bladder carcinoma. Int J Cancer. 2010;126(6):1390-402.

15. Thorner AR, Hoadley KA, Parker JS, Winkel S, Millikan RC, Perou CM. In vitro and in vivo analysis of B-Myb in basal-like breast cancer. Oncogene. 2009;28(5):742-51. 
16. Liu Q, Guo L, Qi H, Lou M, Wang R, Hai B, Xu K, Zhu L, Ding Y, Li C, et al. A MYBL2 complex for RRM2 transactivation and the synthetic effect of MYBL2 knockdown with WEE1 inhibition against colorectal cancer. Cell Death Dis. 2021;12(7):683.

17. Baker SJ, Ma'ayan A, Lieu YK, John P, Reddy MV, Chen EY, Duan Q, Snoeck HW, Reddy EP. B-myb is an essential regulator of hematopoietic stem cell and myeloid progenitor cell development. Proc Natl Acad Sci USA. 2014;111(8):3122-7.

18. Greig KT, Carotta S, Nutt SL. Critical roles for c-Myb in hematopoietic progenitor cells. Semin Immunol. 2008;20(4):247-56.

19. Jin Y, Zhu H, Cai W, Fan X, Wang Y, Niu Y, Song F, Bu Y. B-Myb is upregulated and promotes cell growth and motility in non-small cell lung cancer. Int J Mol Sci. 2017. https://doi.org/10.3390/ijms18060860.

20. Gonda TJ, Leo P, Ramsay RG. Estrogen and MYB in breast cancer: potential for new therapies. Expert Opin Biol Ther. 2008;8(6):713-7.

21. Xu LH, Zhao F, Yang WW, Chen CW, Du ZH, Fu M, Ge XY, Li SL. MYB promotes the growth and metastasis of salivary adenoid cystic carcinoma. Int J Oncol. 2019;54(5):1579-90.

22. Tung CH, Kuo LW, Huang MF, Wu YY, Tsai YT, Wu JE, Hsu KF, Chen YL, Hong TM. MicroRNA-150-5p promotes cell motility by inhibiting c-Mybmediated Slug suppression and is a prognostic biomarker for recurrent ovarian cancer. Oncogene. 2020;39(4):862-76.

23. Yusenko MV, Trentmann A, Andersson MK, Ghani LA, Jakobs A, Arteaga Paz MF, Mikesch JH, von Kries JP, Stenman G, Klempnauer KH. Monensin, a novel potent MYB inhibitor, suppresses proliferation of acute myeloid leukemia and adenoid cystic carcinoma cells. Cancer Lett. 2020;479:61-70

24. Biedenkapp H, Borgmeyer U, Sippel AE, Klempnauer KH. Viral myb oncogene encodes a sequence-specific DNA-binding activity. Nature. 1988;335(6193):835-7.

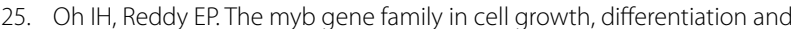
apoptosis. Oncogene. 1999;18(19):3017-33.

26. Vo JN, Cieslik M, Zhang Y, Shukla S, Xiao L, Zhang Y, Wu YM, Dhanasekaran SM, Engelke CG, Cao X, et al. The landscape of circular RNA in cancer. Cell. 2019;176(4):869-881 e813.

27. Rigoutsos I, Lee SK, Nam SY, Anfossi S, Pasculli B, Pichler M, Jing Y, Rodriguez-Aguayo C, Telonis AG, Rossi S, et al. N-BLR, a primate-specific non-coding transcript leads to colorectal cancer invasion and migration. Genome Biol. 2017;18(1):98

28. Washietl S, Kellis M, Garber M. Evolutionary dynamics and tissue specificity of human long noncoding RNAs in six mammals. Genome Res. 2014:24(4):616-28.

29. Esteller M. Non-coding RNAs in human disease. Nat Rev Genet. 2011:12(12):861-74

30. Liang J, Liu X, Xue H, Qiu B, Wei B, Sun K. MicroRNA-103a inhibits gastric cancer cell proliferation, migration and invasion by targeting c-Myb. Cell Prolif. 2015;48(1):78-85.

31. Catalanotto C, Cogoni C, Zardo G. MicroRNA in control of gene expression: an overview of nuclear functions. Int J Mol Sci. 2016. https://doi. org/10.3390/ijms17101712.

32. Kopp F, Mendell JT. Functional classification and experimental dissection of long noncoding RNAs. Cell. 2018;172(3):393-407.

33. Bhan A, Soleimani M, Mandal SS. Long noncoding rna and cancer: a new paradigm. Cancer Res. 2017;77(15):3965-81.

34. Hu S, Shan G. LncRNAs in stem cells. Stem Cells Int. 2016;2016:2681925.

35. Su X, Malouf GG, Chen Y, Zhang J, Yao H, Valero V, Weinstein JN, Spano $J$ J, Meric-Bernstam F, Khayat D, et al. Comprehensive analysis of long non-coding RNAs in human breast cancer clinical subtypes. Oncotarget. 2014;5(20):9864-76.

36. Bartel DP. MicroRNAs: genomics, biogenesis, mechanism, and function. Cell. 2004;116(2):281-97.

37. Cimmino A, Calin GA, Fabbri M, lorio MV, Ferracin M, Shimizu M, Wojcik SE, Aqeilan RI, Zupo S, Dono M, et al. miR-15 and miR-16 induce apoptosis by targeting BCL2. Proc Natl Acad Sci USA. 2005;102(39):13944-9.

38. Li W, Liu JQ, Chen M, Xu J, Zhu D. Circular RNA in cancer development and immune regulation. J Cell Mol Med. 2020. https://doi.org/10.1111/ jcmm.16102.

39. Lee J, Li Z, Brower-Sinning R, John B. Regulatory circuit of human microRNA biogenesis. PLoS Comput Biol. 2007;3(4): e67.
40. Zhao H, Kalota A, Jin S, Gewirtz AM. The c-myb proto-oncogene and microRNA-15a comprise an active autoregulatory feedback loop in human hematopoietic cells. Blood. 2009;113(3):505-16.

41. Martinez I, Dimaio D. B-Myb, cancer, senescence, and microRNAs. Cancer Res. 2011;71(16):5370-3.

42. Wang W, Wu S, Shi Y, Miao Y, Luo X, Ji M, Yao K, He J. c-MYB regulates cell growth and DNA damage repair through modulating MiR-143. FEBS Lett. 2015;589(5):555-64.

43. Vargova K, Curik N, Burda P, Basova P, Kulvait V, Pospisil V, Savvulidi F, Kokavec J, Necas E, Berkova A, et al. MYB transcriptionally regulates the miR-155 host gene in chronic lymphocytic leukemia. Blood. 2011;117(14):3816-25.

44. Haftmann C, Stittrich AB, Zimmermann J, Fang Z, Hradilkova K, Bardua M, Westendorf K, Heinz GA, Riedel R, Siede J, et al. miR-148a is upregulated by Twist1 and T-bet and promotes Th1-cell survival by regulating the proapoptotic gene Bim. Eur J Immunol. 2015;45(4):1192-205.

45. Lang G, White JR, Argent-Katwala MJ, Allinson CG, Weston K. Myb proteins regulate the expression of diverse target genes. Oncogene. 2005;24(8):1375-84

46. Zhang H, Li Y, Huang Q, Ren X, Hu H, Sheng H, Lai M. MiR-148a promotes apoptosis by targeting $\mathrm{Bcl}-2$ in colorectal cancer. Cell Death Differ. 2011;18(11):1702-10

47. Wang Y, Zhang CY, Xia RH, Han J, Sun B, Sun SY, Li J. The MYB/miR-130a/ NDRG2 axis modulates tumor proliferation and metastatic potential in salivary adenoid cystic carcinoma. Cell Death Dis. 2018;9(9):917.

48. Wang W, Yang $Y$, Chen $X$, Shao S, Hu S, Zhang T. MAGI1 mediates tumor metastasis through c-Myb/miR-520h/MAGl1 signaling pathway in renal cell carcinoma. Apoptosis. 2019;24(11-12):837-48.

49. Zhang H, Jiang S, Guo L, Li X. MicroRNA-1258, regulated by c-Myb, inhibits growth and epithelial-to-mesenchymal transition phenotype via targeting SP1 in oral squamous cell carcinoma. J Cell Mol Med. 2019;23(4):2813-21.

50. Vizcaino C, Mansilla S, Portugal J. Sp1 transcription factor: a long-standing target in cancer chemotherapy. Pharmacol Ther. 2015;152:111-24.

51. Basova P, Pospisil V, Savvulidi F, Burda P, Vargova K, Stanek L, Dluhosova M, Kuzmova E, Jonasova A, Steidl U, et al. Aggressive acute myeloid leukemia in PU.1/p53 double-mutant mice. Oncogene. 2014:33(39):4735-45.

52. Lyabin DN, Eliseeva IA, Ovchinnikov LP. YB-1 protein: functions and regulation. Wiley Interdiscip Rev RNA. 2014;5(1):95-110.

53. Johnson TG, Schelch K, Lai K, Marzec KA, Kennerson M, Grusch M, Reid G, Burgess A. YB-1 knockdown inhibits the proliferation of mesothelioma cells through multiple mechanisms. Cancers. 2020. https://doi. org/10.3390/cancers12082285.

54. Zhao X, Zhang W, Ji W. YB-1 promotes laryngeal squamous cell carcinoma progression by inducing miR-155 expression via c-Myb. Future Oncol. 2018;14(16):1579-89.

55. Yang $X, H u Q$, Hu LX, Lin XR, Liu JQ, Lin X, Dinglin XX, Zeng JY, Hu H, Luo ML, et al. miR-200b regulates epithelial-mesenchymal transition of chemo-resistant breast cancer cells by targeting FN1. Discov Med. 2017:24(131):75-85

56. Manavalan TT, Teng Y, Litchfield LM, Muluhngwi P, Al-Rayyan N, Klinge CM. Reduced expression of miR-200 family members contributes to antiestrogen resistance in LY2 human breast cancer cells. PLoS One. 2013;8(4): e62334.

57. Rogers TJ, Christenson JL, Greene LI, O'Neill KI, Williams MM, Gordon MA, Nemkov T, D'Alessandro A, Degala GD, Shin J, et al. Reversal of triple-negative breast cancer EMT by miR-200c decreases tryptophan catabolism and a program of immunosuppression. Mol Cancer Res. 2019:17(1):30-41.

58. Gao Y, Zhang W, Liu C, Li G. miR-200 affects tamoxifen resistance in breast cancer cells through regulation of MYB. Sci Rep. 2019;9(1):18844.

59. Pieraccioli M, Imbastari F, Antonov A, Melino G, Raschella G. Activation of miR200 by c-Myb depends on ZEB1 expression and miR200 promoter methylation. Cell Cycle. 2013;12(14):2309-20.

60. Chen J, Chen X. MYBL2 is targeted by miR-143-3p and regulates breast cancer cell proliferation and apoptosis. Oncol Res. 2018;26(6):913-22.

61. Wu Z, Huang X, Huang X, Zou Q, Guo Y. The inhibitory role of Mir-29 in growth of breast cancer cells. J Exp Clin Cancer Res. 2013;32:98. 
62. Wang XL, Wang WF, Hao JM. Effect of MiR-96 on cell invasion and apoptosis in pediatric acute myeloid leukemia via regulating MYB. Zhongguo Shi Yan Xue Ye Xue Za Zhi. 2021;29(2):439-44.

63. Zauli G, Voltan R, di lasio MG, Bosco R, Melloni E, Sana ME, Secchiero P. miR-34a induces the downregulation of both E2F1 and B-Myb oncogenes in leukemic cells. Clin Cancer Res. 2011;17(9):2712-24.

64. Chung EY, Dews M, Cozma D, Yu D, Wentzel EA, Chang TC, Schelter JM Cleary MA, Mendell JT, Thomas-Tikhonenko A. C-Myb oncoprotein is an essential target of the dleu2 tumor suppressor microRNA cluster. Cancer Biol Ther. 2008;7(11):1758-64.

65. Yang H, Dai X, Ai Z, Ren R, Gao C, Han J, Ma Y. MicroRNA-16 regulates myeloblastosis oncogene expression to affect differentiation of acute leukemia cells. Clin Lab. 2019. https://doi.org/10.7754/Clin.Lab.2018. 181008.

66. Hornick NI, Doron B, Abdelhamed S, Huan J, Harrington CA, Shen R, Cambronne XA, Chakkaramakkil Verghese S, Kurre P. AML suppresses hematopoiesis by releasing exosomes that contain microRNAs targeting c-MYB. Sci Signal. 2016;9(444):ra88.

67. Mets E, Van der Meulen J, Van Peer G, Boice M, Mestdagh P, Van de Walle I, Lammens T, Goossens S, De Moerloose B, Benoit Y, et al. MicroRNA193b-3p acts as a tumor suppressor by targeting the MYB oncogene in T-cell acute lymphoblastic leukemia. Leukemia. 2015;29(4):798-806.

68. Lu J, Zhang M, Yang X, Cui T, Dai J. MicroRNA-548c-3p inhibits T98G glioma cell proliferation and migration by downregulating c-Myb. Oncol Lett. 2017;13(5):3866-72.

69. Zhang B, Yuan F, Liu J, Li Y, Zhou F, Liu X, Hao Z, Li Q, Zheng Y, Wang W. Hsa-miR-495 acts as a tumor suppressor gene in glioma via the negative regulation of MYB. Mol Med Rep. 2016;14(1):977-82.

70. Barroga CF, Pham H, Kaushansky K. Thrombopoietin regulates c-Myb expression by modulating micro RNA 150 expression. Exp Hematol. 2008;36(12):1585-92.

71. Chen S, Wang Z, Dai X, Pan J, Ge J, Han X, Wu Z, Zhou X, Zhao T. Re-expression of microRNA-150 induces EBV-positive Burkitt lymphoma differentiation by modulating c-Myb in vitro. Cancer Sci. 2013:104(7):826-34

72. Srutova K, Curik N, Burda P, Savvulidi F, Silvestri G, Trotta R, Klamova H, Pecherkova P, Sovova Z, Koblihova J, et al. BCR-ABL1 mediated miR-150 downregulation through MYC contributed to myeloid differentiation block and drug resistance in chronic myeloid leukemia. Haematologica. 2018;103(12):2016-25.

73. Feng J, Yang Y, Zhang P, Wang F, Ma Y, Qin H, Wang Y. miR-150 functions as a tumour suppressor in human colorectal cancer by targeting c-Myb. J Cell Mol Med. 2014;18(10):2125-34.

74. Cui X, Zhao C, Yao X, Qian B, Su C, Ren Y, Yao Z, Gao X, Yang J. SND1 acts as an anti-apoptotic factor via regulating the expression of IncRNA UCA1 in hepatocellular carcinoma. RNA Biol. 2018;15(10):1364-75.

75. Gan S, Ma P, Ma J, Wang W, Han H, Chen L, Li X, Wu F, Sun H. Knockdown of ZFAS1 suppresses the progression of acute myeloid leukemia by regulating microRNA-150/Sp1 and microRNA-150/Myb pathways. Eur J Pharmacol. 2019;844:38-48.

76. Tripathi V, Shen Z, Chakraborty A, Giri S, Freier SM, Wu X, Zhang Y, Gorospe M, Prasanth SG, Lal A, et al. Long noncoding RNA MALAT1 controls cell cycle progression by regulating the expression of oncogenic transcription factor B-MYB. PLoS Genet. 2013;9(3): e1003368.

77. Prouse MB, Campbell MM. The interaction between MYB proteins and their target DNA binding sites. Biochim Biophys Acta. 2012;1819(1):67-77.

78. Mo Y, He L, Lai Z, Wan Z, Chen Q, Pan S, Li L, Li D, Huang J, Xue F, et al. LINC01287 regulates tumorigenesis and invasion via miR-298/MYB in hepatocellular carcinoma. J Cell Mol Med. 2018;22(11):5477-85.

79. Pan L, Liang W, Fu M, Huang ZH, Li X, Zhang W, Zhang P, Qian H, Jiang PC, Xu WR, et al. Exosomes-mediated transfer of long noncoding RNA ZFAS1 promotes gastric cancer progression. J Cancer Res Clin Oncol. 2017;143(6):991-1004

80. Jia YC, Wang JY, Liu YY, Li B, Guo H, Zang AM. LnCRNA MAFG-AS1 facilitates the migration and invasion of NSCLC cell via sponging miR339-5p from MMP15. Cell Biol Int. 2019;43(4):384-93.

81. Jia H, Wu D, Zhang Z, Li S. Regulatory effect of the MAFGAS1/ miR1505p/MYB axis on the proliferation and migration of breast cancer cells. Int J Oncol. 2020. https://doi.org/10.3892/ijo.2020.5150.
82. Huang Y, Zhang J, Hou L, Wang G, Liu H, Zhang R, Chen X, Zhu J. LncRNA AK023391 promotes tumorigenesis and invasion of gastric cancer through activation of the PI3K/Akt signaling pathway. J Exp Clin Cancer Res. 2017;36(1):194.

83. Zhuang R, Zhang X, Lu D, Wang J, Zhuo J, Wei X, Ling Q, Xie H, Zheng $S, X U X$. IncRNA DRHC inhibits proliferation and invasion in hepatocellular carcinoma via c-Myb-regulated MEK/ERK signaling. Mol Carcinog. 2019;58(3):366-75.

84. Zhou X, Liu M, Deng G, Chen L, Sun L, Zhang Y, Luo C, Tang J. IncRNA LOC102724169 plus cisplatin exhibit the synergistic anti-tumor effect in ovarian cancer with chronic stress. Mol Ther Nucleic Acids. 2021:24:294-309.

85. Chang YS, Lee YT, Yen JC, Chang YC, Lin LL, Chan WL, Chang WC, Lin SY, Chang JG. Long noncoding RNA NTT context-dependently regulates MYB by interacting with activated complex in hepatocellular carcinoma cells. Front Oncol. 2021;11: 592045.

86. Lan T, Yuan K, Yan X, Xu L, Liao H, Hao X, Wang J, Liu H, Chen X, Xie K, et al. LncRNA SNHG10 facilitates hepatocarcinogenesis and metastasis by modulating Its homolog SCARNA13 via a positive feedback loop. Cancer Res. 2019;79(13):3220-34.

87. Lin Z, Long F, Zhao M, Zhang X, Yang M. The role of circular RNAs in hematological malignancies. Genomics. 2020;112(6):4000-8.

88. Chen X, Yang T, Wang W, Xi W, Zhang T, Li Q, Yang A, Wang T. Circular RNAs in immune responses and immune diseases. Theranostics. 2019:9(2):588-607.

89. Lei M, Zheng G, Ning Q, Zheng J, Dong D. Translation and functional roles of circular RNAs in human cancer. Mol Cancer. 2020;19(1):30.

90. Ebbesen KK, Hansen TB, Kjems J. Insights into circular RNA biology. RNA Biol. 2017;14(8):1035-45

91. Qiu L, Xu H, Ji M, Shang D, Lu Z, Wu Y, Tu Z, Liu H. Circular RNAs in hepatocellular carcinoma: biomarkers, functions and mechanisms. Life Sci. 2019;231: 116660.

92. Arnaiz E, Sole C, Manterola L, Iparraguirre L, Otaegui D, Lawrie CH. CircRNAs and cancer: biomarkers and master regulators. Semin Cancer Biol. 2019;58:90-9.

93. Li R, Jiang J, Shi H, Qian H, Zhang X, Xu W. CircRNA: a rising star in gastric cancer. Cell Mol Life Sci. 2020;77(9):1661-80.

94. Chaichian S, Shafabakhsh R, Mirhashemi SM, Moazzami B, Asemi Z. Circular RNAs: a novel biomarker for cervical cancer. J Cell Physiol. 2020;235(2):718-24.

95. Du WW, Zhang C, Yang W, Yong T, Awan FM, Yang BB. Identifying and characterizing circRNA-protein interaction. Theranostics. 2017;7(17):4183-91.

96. Yang L, Han X, Zhang C, Sun C, Huang S, Xiao W, Gao Y, Liang Q, Luo F, Lu W, et al. Hsa_circ_0060450 negatively regulates type I interferoninduced inflammation by serving as miR-199a-5p sponge in type 1 Diabetes mellitus. Front Immunol. 2020;11: 576903.

97. Zeng K, Chen X, Xu M, Liu X, Hu X, Xu T, Sun H, Pan Y, He B, Wang S. CircHIPK3 promotes colorectal cancer growth and metastasis by sponging miR-7. Cell Death Dis. 2018;9(4):417.

98. Zhang C, Liu W, Li F, Feng Y, Li Y, Wang J. Hsa_circ_0015326 promotes the proliferation, invasion and migration of ovarian cancer through miR-127-3p/MYB. Cancer Manag Res. 2021;13:2265-77.

99. Javadian M, Gharibi T, Shekari N, Abdollahpour-Alitappeh M, Mohammadi A, Hossieni A, Mohammadi H, Kazemi T. The role of microRNAs regulating the expression of matrix metalloproteinases (MMPs) in breast cancer development, progression, and metastasis. J Cell Physiol. 2019;234(5):5399-412.

100. Yongchun Z, Linwei T, Xicai W, Lianhua Y, Guangqiang Z, Ming Y, Guanjian L, Yujie L, Yunchao H. MicroRNA-195 inhibits non-small cell lung cancer cell proliferation, migration and invasion by targeting MYB. Cancer Lett. 2014;347(1):65-74.

101. Knopfova L, Benes P, Pekarcikova L, Hermanova M, Masarik M, Pernicova Z, Soucek K, Smarda J. c-Myb regulates matrix metalloproteinases 1/9, and cathepsin D: implications for matrix-dependent breast cancer cell invasion and metastasis. Mol Cancer. 2012;11:15.

102. Deng Q, Wu L, Li Y, Zou L. MYBL2 in synergy with CDC20 promotes the proliferation and inhibits apoptosis of gastric cancer cells. Adv Clin Exp Med. 2021;30(9):957-66. 
103. Zhang D, Zhou S, Liu B. Identification and validation of an individualized EMT-related prognostic risk score formula in gastric adenocarcinoma patients. Biomed Res Int. 2020;2020: 7082408.

104. Sun X, Zhang C, Cao Y, Liu E. miR-150 suppresses tumor growth in melanoma through downregulation of MYB. Oncol Res. 2019;27(3):317-23.

105. Wang $M$, Yang $W$, Li M, Li Y. Low expression of miR-150 in pediatric intestinal Burkitt lymphoma. Exp Mol Pathol. 2014;96(2):261-6.

106. Asl ER, Amini M, Najafi S, Mansoori B, Mokhtarzadeh A, Mohammadi A, Lotfinejad P, Bagheri M, Shirjang S, Lotfi Z, et al. Interplay between MAPK/ERK signaling pathway and MicroRNAs: a crucial mechanism regulating cancer cell metabolism and tumor progression. Life Sci. 2021;278: 119499

107. Wong RS. Apoptosis in cancer: from pathogenesis to treatment. J Exp Clin Cancer Res. 2011:30:87.

108. Zhu X, Lu X. MiR-423-5p inhibition alleviates cardiomyocyte apoptosis and mitochondrial dysfunction caused by hypoxia/reoxygenation through activation of the wnt/beta-catenin signaling pathway via targeting MYBL2. J Cell Physiol. 2019;234(12):22034-43.

109. Xu C, He Z, Lin C, Shen Z. MiR-30b-5p inhibits proliferation and promotes apoptosis of medulloblastoma cells via targeting MYB protooncogene like 2 (MYBL2). J Investig Med. 2020;68(6):1179-85.

110. Gu J, Lu Z, Ji C, Chen Y, Liu Y, Lei Z, Wang L, Zhang HT, Li X. Melatonin inhibits proliferation and invasion via repression of miRNA-155 in glioma cells. Biomed Pharmacother. 2017:93:969-75.

111. Kim J, Zhang Y, Skalski M, Hayes J, Kefas B, Schiff D, Purow B, Parsons S, Lawler S, Abounader R. microRNA-148a is a prognostic oncomiR that targets MIG6 and BIM to regulate EGFR and apoptosis in glioblastoma. Can Res. 2014;74(5):1541-53.

112. Wefers AK, Stichel D, Schrimpf D, Coras R, Pages M, Tauziède-Espariat A, Varlet P, Schwarz D, Söylemezoglu F, Pohl U, et al. Isomorphic diffuse glioma is a morphologically and molecularly distinct tumour entity with recurrent gene fusions of MYBL1 or MYB and a benign disease course. Acta Neuropathol. 2020;139(1):193-209.

113. Zhang J, Luo N, Luo Y, Peng Z, Zhang T, Li S. microRNA-150 inhibits human CD133-positive liver cancer stem cells through negative regulation of the transcription factor c-Myb. Int J Oncol. 2012;40(3):747-56.

114. Navarro-Imaz H, Ochoa B, Garcia-Arcos I, Martinez MJ, Chico Y, Fresnedo $\mathrm{O}$, Rueda Y. Molecular and cellular insights into the role of SND1 in lipid metabolism. Biochim Biophys Acta Mol Cell Biol Lipids. 2020;1865(5): 158589.

115. Ramjiawan RR, Griffioen AW, Duda DG. Anti-angiogenesis for cancer revisited: is there a role for combinations with immunotherapy? Angiogenesis. 2017;20(2):185-204.

116. Strijkers GJ, Kluza E, Van Tilborg GA, van der Schaft DW, Griffioen AW, Mulder WJ, Nicolay K. Paramagnetic and fluorescent liposomes for target-specific imaging and therapy of tumor angiogenesis. Angiogenesis. 2010;13(2):161-73.

117. Ramsay RG, Barton AL, Gonda TJ. Targeting c-Myb expression in human disease. Expert Opin Ther Targets. 2003;7(2):235-48.

118. Yang $H$, Zhang $H$, Ge S, Ning T, Bai M, Li J, Li S, Sun W, Deng T, Zhang $\mathrm{L}$, et al. Exosome-derived miR-130a activates angiogenesis in gastric cancer by targeting C-MYB in vascular endothelial cells. Mol Ther. 2018:26(10):2466-75

119. Frezzetti D, Gallo M, Maiello MR, D'Alessio A, Esposito C, Chicchinelli $\mathrm{N}$, Normanno N, De Luca A. VEGF as a potential target in lung cancer. Expert Opin Ther Targets. 2017;21(10):959-66.

120. Deng $T$, Zhang $H$, Yang $H$, Wang $H$, Bai M, Sun W, Wang $X$, Si Y, Ning T, Zhang $L$, et al. Exosome miR-155 derived from gastric carcinoma promotes angiogenesis by targeting the c-MYB/NEGF axis of endothelial cells. Mol Ther Nucleic Acids. 2020;19:1449-59.

121. Li P, Xin H, Lu L. Extracellular vesicle-encapsulated microRNA-424 exerts inhibitory function in ovarian cancer by targeting MYB. J Transl Med. 2021;19(1):4.

122. Wan L, Pantel K, Kang Y. Tumor metastasis: moving new biological insights into the clinic. Nat Med. 2013;19(11):1450-64.

123. Fidler IJ, Kripke ML. The challenge of targeting metastasis. Cancer Metastasis Rev. 2015;34(4):635-41.

124. Feng $X$, Jia S, Martin TA, Jiang WG. Regulation and involvement in cancer and pathological conditions of MAGI1, a tight junction protein. Anticancer Res. 2014;34(7):3251-6.
125. Zhang J, Liu W, Shen F, Ma X, Liu X, Tian F, Zeng W, Xi X, Lin Y. The activation of microRNA-520h-associated TGF-beta1/c-Myb/Smad7 axis promotes epithelial ovarian cancer progression. Cell Death Dis. 2018;9(9):884

126. X X Y, Yao Y, Jiang $X$, Zhong $X$, Wang $Z$, Li C, Kang $P$, Leng $K$, Ji $D$, Li Z, et al. SP1-induced upregulation of IncRNA SPRY4-IT1 exerts oncogenic properties by scaffolding EZH2/LSD1/DNMT1 and sponging miR-101-3p in cholangiocarcinoma. J Exp Clin Cancer Res. 2018;37(1):81.

127. Zhang JP, Zhang H, Wang HB, Li YX, Liu GH, Xing S, Li MZ, Zeng MS. Down-regulation of Sp1 suppresses cell proliferation, clonogenicity and the expressions of stem cell markers in nasopharyngeal carcinoma. J Transl Med. 2014;12:222.

128. Mowla SN, Lam EW, Jat PS. Cellular senescence and aging: the role of B-MYB. Aging Cell. 2014;13(5):773-9.

129. Jiang W, Wei K, Pan C, Li H, Cao J, Han X, Tang Y, Zhu S, Yuan W, He Y, et al. MicroRNA-1258 suppresses tumour progression via GRB2/Ras/Erk pathway in non-small-cell lung cancer. Cell Prolif. 2018;51 (6): e12502.

130. Hong L, Lai M, Chen M, Xie C, Liao R, Kang YJ, Xiao C, Hu WY, Han J, Sun P. The miR-17-92 cluster of microRNAs confers tumorigenicity by inhibiting oncogene-induced senescence. Cancer Res. 2010;70(21):8547-57.

131. Spagnuolo M, Regazzo G, De Dominici M, Sacconi A, Pelosi A, Korita E, Marchesi F, Pisani F, Magenta A, Lulli V, et al. Transcriptional activation of the miR-17-92 cluster is involved in the growth-promoting effects of MYB in human Ph-positive leukemia cells. Haematologica. 2019;104(1):82-92.

132. Zhang XY, Li YF, Ma H, Gao YH. Regulation of MYB mediated cisplatin resistance of ovarian cancer cells involves miR-21-wnt signaling axis. Sci Rep. 2020;10(1):6893.

133. Lee YJ, Kang YR, Lee SY, Jin Y, Han DC, Kwon BM. Ginkgetin induces G2-phase arrest in HCT116 colon cancer cells through the modulation of bMyb and miRNA34a expression. Int J Oncol. 2017:51 (4):1331-42.

134. Zuber J, Rappaport AR, Luo W, Wang E, Chen C, Vaseva AV, Shi J, Weissmueller S, Fellmann C, Taylor MJ, et al. An integrated approach to dissecting oncogene addiction implicates a Myb-coordinated selfrenewal program as essential for leukemia maintenance. Genes Dev. 2011;25(15):1628-40.

135. Cross RS, Malaterre J, Davenport AJ, Carpinteri S, Anderson RL, Darcy PK, Ramsay RG. Therapeutic DNA vaccination against colorectal cancer by targeting the MYB oncoprotein. Clin Transl Immunol. 2015;4(1):e30.

136. Walf-Vorderwulbecke V, Pearce K, Brooks T, Hubank M, van den HeuvelEibrink MM, Zwaan CM, Adams S, Edwards D, Bartram J, Samarasinghe $\mathrm{S}$, et al. Targeting acute myeloid leukemia by drug-induced c-MYB degradation. Leukemia. 2018;32(4):882-9.

137. Bhattacharya S, Patel KK, Dehari D, Agrawal AK, Singh S. Melatonin and its ubiquitous anticancer effects. Mol Cell Biochem. 2019;462(1-2):133-55.

138. Anastasiadou E, Seto AG, Beatty X, Hermreck M, Gilles ME, Stroopinsky D, Pinter-Brown LC, Pestano L, Marchese C, Avigan D, et al. Cobomarsen, an oligonucleotide inhibitor of miR-155, Slows DLBCL tumor cell growth in vitro and in vivo. Clin Cancer Res. 2021;27(4):1139-49.

139. Trang P, Wiggins JF, Daige CL, Cho C, Omotola M, Brown D, Weidhaas JB, Bader AG, Slack FJ. Systemic delivery of tumor suppressor microRNA mimics using a neutral lipid emulsion inhibits lung tumors in mice. Mol Ther. 2011;19(6):1116-22.

140. Beg MS, Brenner AJ, Sachdev J, Borad M, Kang YK, Stoudemire J, Smith S, Bader AG, Kim S, Hong DS. Phase I study of MRX34, a liposomal miR34a mimic, administered twice weekly in patients with advanced solid tumors. Invest New Drugs. 2017;35(2):180-8.

141. Liu XG, Lu X, Gao W, Li P, Yang H. Structure, synthesis, biosynthesis, and activity of the characteristic compounds from Ginkgo biloba L. Nat Prod Rep. 2021. https://doi.org/10.1039/D1NP00026H.

142. Plaisier CL, O'Brien S, Bernard B, Reynolds S, Simon Z, Toledo CM, Ding Y, Reiss DJ, Paddison PJ, Baliga NS. Causal mechanistic regulatory network for glioblastoma deciphered using systems genetics network analysis. Cell Syst. 2016;3(2):172-86.

\section{Publisher's Note}

Springer Nature remains neutral with regard to jurisdictional claims in published maps and institutional affiliations. 